\title{
Butterfly effect in periodontology; can we control the initial condition to prevent periodontal disease?
}

\author{
Aous Dannan ${ }^{1 *}$ and Fozi Dannan ${ }^{2}$ \\ ${ }^{1}$ Lecturer of Periodontics, Department of Periodontology, Faculty of Dentistry, Syrian Private University, Damascus, Syria \\ ${ }^{2}$ Professor of Mathematics, Department of Basic Sciences, Faculty of Informatics and communication's Engineering, Arab International University, Damascus, Syria
}

\begin{abstract}
While applying linear models to human systems and their elements has improved our understanding of their structure and function, such models often fall short of explaining experimental results or predicting future abnormalities in complex nonlinear systems.

Starting from the fact that the periodontium is a complex system in the body, this paper demonstrates possible reflection of chaos theory and the concept of butterfly effect in the field of periodontology. The application of sub-antimicrobial-dose Doxycycline (SDD), as an initial turning point and a host modulator factor, to prevent further progression of the periodontal disease, has been briefly discussed, and a possible mathematical model for the action of SDD has been demonstrated as well.

Linear and nonlinear modeling will serve a complementary role in explaining simple and complex system behavior manifest within human systems. Knowledge of chaos may also prove valuable in managing illness.
\end{abstract}

\section{Introduction}

In general, behavior of any system in the nature is distinct from the behavior of its parts or elements. These elements interact with each other directly and indirectly to modulate the system function. The mechanistic view of nature involves reducing systems into their component parts (elements) in an attempt to understand them [1]. This is the basis of linear system analysis, where output is proportional to or can be determined through applying simple differential equations to the input.

Yet systems within nature, including the human body, frequently lack mechanical periodicity or linear dynamics and thus are referred to as nonlinear systems [2]. Within nonlinear systems, output is usually not proportional to input, and output for the same input value may not be constant over time. Furthermore, in contrast to linear systems, breaking a nonlinear system down into its elements and analyzing those parts under controlled conditions does not accurately reflect the complex behavior present, nor capture the dynamic relationships operating between various elements $[3,4]$.

\section{The periodontium as a unique system}

The periodontium is a supporting structure that surrounds and supports the teeth. It consists of different tissues including the gingiva, the cementum, the periodontal ligament, and the alveolar supporting bone. As a unique "system", the periodontium is a collection of interacting elements.

In general, system behavior may be simple or complex, static or dynamic. Simple systems follow basic rules; thus with knowledge of the elements that form the system and the rules that govern them, one can accurately predict the system behavior under various conditions. However, complex nonlinear systems, such as the periodontium, have been defined as "systems or wholes consisting of an extremely large and variable number of component parts, where the individual components display marked variability over time, and are characterized by a high degree of connectivity or interdependence between variables" [5]. Rather than exhibiting random behavior, most complex nonlinear systems will tend towards and manifest certain states more often, called "attractors." This leads to "Emergence," which describes the order that arises from what on initial inspection appears to be disorder, further, such emergence can arise from local and simple rules within the system [6].

The periodontal ligament, for example, encounters several types of cells (e.g. osteoblasts, cementoblasts, fibroblasts, stem cells) that interact with each other by means of messengers or signals (immunoglobulins, cytokines, interleukins). This system is forever in a state of flux, with complex offensive and defenses maneuvers mounted against a foray of invaders. Even when exposed to an identical stimulus, this system can respond differently and various behaviors emerge depending on multiple external and internal influences.

\section{Chaos theory and butterfly effect}

In the Twentieth Century, nonlinear theory came into the spotlight by accident. In 1961, Edward Lorenz, a mathematician-meteorologist working at the Massachusetts Institute of Technology, observed what he believed was order masquerading as randomness. He used a simple mathematical model of weather patterns and a computer capable

Correspondence to: Aous Dannan, Department of Periodontology, Faculty of Dentistry, Syrian Private University, Damascus, Syria; E-mail: aousdannan@yahoo.com

Key words: periodontal disease, chaos, butterfly effect, models

Received: November 01, 2015; Accepted: December 14, 2015; Published: December 17, 2015 
of performing multiple iterations (repetitions). After accidentally inputting an incorrect decimal point in a number, he noted that small variations in initial conditions (temperature or atmospheric pressure) would cascade through various iterations into remarkably different output (weather conditions) $[7,8]$.

This and other observations by Lorenz were the earliest reference to "chaos theory". Chaos is defined as the quality of a deterministic mathematical system in which an extreme sensitivity to initial conditions exists [9]. The mathematical calculations involved in modeling chaos theory requires large numbers of calculations, often iterated (repeated), thus this field has blossomed in parallel with the computer revolution [6]. Chaotic behavior or that behaving according to "chaos theory" describes dynamic behavior that is sensitive to initial conditions, and parameter changes, deterministic (described by rules), aperiodic (does not repeat itself), and restricted within certain parameters. Chaos theory is being applied to nonlinear medical systems and could thus be reflected onto the periodontium as a unique chaotic system.

Sensitive dependence on initial conditions means that small variations in initial conditions result in large, divergent and dynamic transformations in outputs events. In medicine, sensitivity to initial conditions has been used by one group to convert a chaotic pattern of arrhythmia (unstable) to a low-order periodic pattern (stable) by single intermittent stimuli using a "proportional perturbation feedback" method.

By delivering an electrical impulse at the right time and place, it is possible to bring about an alteration in the heart's electrical dynamics $[10,11]$. In addition, it is possible to move from non-chaos to chaos in some systems by altering period and amplitude modulation. However, similar reflection of such principles in Periodontology is not under focus yet.

\section{Possible reflection of butterfly effect-dependent concepts for the prevention of periodontal disease}

Periodontal disease, or periodontitis, is a chronic infectious inflammatory disease that affects the periodontium and gradually destroys the tooth-supporting alveolar bone.

Periodontal diseases are caused by bacterially-derived factors and antigens that stimulate a local inflammatory reaction and activation of the innate immune system $[12,13]$. These in turn activate different innate immunity pathways, including cytokines and chemokines production that recruit nonresident leukocytes to periodontal space. In turn, activated leukocytes, the adaptive immunity cells, secrete proinflammatory cytokines and chemokines in the tissues [14]. It is now accepted that the amplification of this initial local host response (lasting approximately 21 days) results in the propagation of the inflammation and leads to the destruction of soft and mineralized periodontal tissues [15].

Modulation of host response in a trial to control the initial condition of the body to face an upcoming periodontal disease is considered a novel promising therapy and consists in modulating the host defense mechanisms in response to inflammation.

The concept of host modulation has been universally implemented since last few decades by the physicians in treatment of chronic diseases such as rheumatoid arthritis and osteoporosis [16]. Although, Paul Goldhaber and Max Goodson began to implicate Arachidonic acid metabolites as important inflammatory mediators of the bone loss in periodontitis in the 1970s but the concept of host modulation in dentistry was introduced by Williams in 1990 [17], concluding that "There are compelling data from animal and human trials indicating that pharmacologic agents that modulate the host responses believed to be involved in the pathogenesis of periodontal destruction may be effective in slowing progression of periodontal disease".

Immediately after the discovery, first described in 1983 [18], that Tetracyclines (TCs) can inhibit host-derived collagenase (and later, other matrix metalloproteinases (MMPs) as well), and by mechanisms independent of the antibacterial property of these drugs, a strategy was developed to formulate a low-dose TC that could be administered long-term for the treatment and management of chronic periodontitis without antibiotic side-effects, such as photosensitivity, gastrointestinal disturbance and colonization with antibiotic-resistant bacteria $[19,20]$. Initially, a low-dose of Minocycline was tested [21] but was soon replaced by low-dose Doxycycline [22,23]. Moreover, these early studies demonstrated that a 2-3 week regimen of low-dose (now called subantimicrobial-dose) Doxycycline, although it did reduce collagenase activity in the human periodontal pocket (the gingival crevicular fluid or GCF) and in the gingival tissue [24], did not produce a lasting effect; that is, upon cessation of drug therapy, the reduced collagenase activity rebounded back to the high levels seen in placebo-treated subjects [25]. In contrast, longer term regimens of SDD (3-9 months duration) did produce a prolonged effect even after cessation of drug administration [26] which may reflect the persistence of Doxycycline in the bone and soft tissues of the periodontium extending the duration of its efficacy.

Several decades ago, experimental low-dose Doxycycline formulations were prepared containing progressively lower amounts of the drug per capsule ranging from 100, 50, 40, 30, 20 and, finally, $10 \mathrm{mg}$. Finally, the dosage regimen of $20 \mathrm{mg}$ b.i.d. was found to be safe and effective [27]. Recently, a more advanced novel sustained release formulation was designed (containing two types of Doxycycline 'beads') which resulted in no adverse events significantly different from placebo-treated subjects, in extensive FDA-approved clinical trials. Based on extensive, multi-institutional, double-blind, placebocontrolled clinical trials, SDD is the first ever MMP-inhibitor drug approved for any disease, and the first systemically administered drug approved by the US FDA, Canadian and European regulatory agencies as adjunctive host-modulating therapy for periodontitis. Emingil et al. [28] reported that a 3-month regimen of SDD adjunctive to nonsurgical periodontal therapy produced a therapeutic benefit for at least a 12 -month period.

In a 2-year, double-blinded, randomized clinical trial, Koppikar and Agrawal [9] found that a ninety-day SDD regimen in postmenopausal women significantly reduced the serum inflammatory biomarker C-reactive protein (CRP) over a 2 -year period. Recently, a comprehensive review conducted by Shinwari et al. [30] demonstrated that SDD was an effective adjunct therapy when used in dosage of 20 mg twice daily for minimum 3-month duration in various periodontal diseases with predictable clinical outcomes. It was also recommended that future clinical research on anti-cytokine drugs, chemically modified tetracycline and other host modulation therapy agents should be conducted so that new drugs were available with highly predictable results.

\section{Demonstrating the effect of SDD by means of a mathematical model}

As mentioned above, SDD would reduce collagenase activity, or amount, in the human periodontal pocket. 
Assuming that $\left(\mathrm{X}_{\mathrm{t}}\right)$ is the amount of collagenase in the periodontal pocket at time $(\mathrm{t})$, the question would be: what is the amount of this enzyme at time $(\mathrm{t}+1)$ ?, denoted by $\left(\mathrm{X}_{(\mathrm{t}+1)}\right)$. Such a relationship can be represented in the general form:

$$
\mathrm{X}_{(\mathrm{t}+1)}=\mathrm{F}\left(\mathrm{X}_{(\mathrm{t})}\right) \text {, }
$$

where $\mathrm{F}(\mathrm{X})$ is called "density dependent", or, mathematically, "function dependence", and the relation itself is called "non-linear difference equation of the first order".

If $\mathrm{F}(\mathrm{X})$ is linear, then we have:

$$
\mathrm{X}_{(\mathrm{t}+1)}=\mathrm{aX} \mathrm{X}_{(\mathrm{t})} \text {, }
$$

where (a) is a real constant number.

In this case the amount of collagenase in the periodontal pocket at the next period depends linearly on the previous amount recorded. Therefore, one can predict the examined amount of enzyme after $(\mathrm{k})$ periods of time. Therefore

$$
\begin{aligned}
& \mathrm{X}_{(\mathrm{t}+2)}=\mathrm{a} \mathrm{X}_{(\mathrm{t}+1)}=\mathrm{a}^{2} \mathrm{X}_{(\mathrm{t})} \\
& \text { and } \\
& \mathrm{X}_{(\mathrm{t}+\mathrm{k})}=\mathrm{a}^{\mathrm{k}} \mathrm{X}_{(\mathrm{t})}
\end{aligned}
$$

However, trying to express the pattern of collagenase reduction by means of such linear models could not be considered realistic due to the complexity of the system we are examining (i.e. the periodontium), in which enzyme activities depend on several stimuli(s) and/or inhibitors.

When the system is modelized by the simple non-linear model:

$$
\mathrm{X}_{(\mathrm{t}+1)}=\mathrm{rX}_{(\mathrm{t})}\left(1-\mathrm{X}_{(\mathrm{t})}\right) \text {, }
$$

where $(r)$ is a real constant number, then we can predict more about the behavior of collagenase activity (or amount) in the periodontal pocket in the future. This behavior is very complicated.

This model is called "logistic equation", and was firstly published by RM May in 1974 [31].

Accordingly, for the prediction of collagenase amount in the periodontal pocket, which is assumed to be reduced overtime due to the SDD delivering, we can use a mathematical model as follows:

$$
\mathrm{X}_{(\mathrm{t}+1)}=\mathrm{rX}_{(\mathrm{t})}\left(1-\mathrm{X}_{(\mathrm{t})}\right)-\mathrm{bX}_{(\mathrm{t})}^{3}
$$

where (b) is a positive constant related to all biological factors that play role in changing the amount and/or the activity of collagenase.

Clearly, this model is not simple, but it is close to the real behavior of the discussed system.

We assume that the concept of delivering SDD for patients in order to prevent some long-run kind of periodontal disease is a clinical reflection of butterfly effect theory, since a small variation of the patient's initial condition (i.e. inhibition of host-derived collagenase) would result in a further turn-over of the whole body (i.e. long-turn resistance against periodontal disease).

\section{Conclusion}

Chaos theory is providing new insights into understanding normal as well as abnormal behavior within complex systems such as the periodontium. Applications of chaos theory may detect disease in its early stages or "early warming." The development of periodontitis relies on multiple factors. The disease is of poly-microbial pathogenesis since different types of bacteria are the initiators of the inflammatory process. Innate immunity is the first line of host defense and resistance to infection. Mechanical removal of infectious agents in the gingival tissues together with SDD administration as host response modulator is the only current treatment in the care of periodontitis, and could be considered as a reflection of the butterfly effect theory in the field of periodontology. These approaches attempt to manage the inflammation and control the tissue damage. However, the complexity of pathways involved in the host response drives differences in the clinical manifestation and disease progression, possibly requiring different therapeutic approaches. The use of mathematical models would enable the researchers to predict the pattern of activity related to the drug and the conditions of enzyme response in the periodontium. An important challenge is to understand the different roles of inflammation mediators, their cellular source, their sites of action, and possibly how to control them at an early stage in order to get future and long-distance positive effect.

\section{References}

1. Mikulecky DC (1996) Complexity, communication between cells, and identifying the functional components of living systems: some observations. Acta Biotheoretica 44: 179-208.

2. Philippe P Mansi O (1998) Nonlinearity in the epidemiology of complex health and disease processes. Theor Med Bioeth 19: 591-607. [Crossref]

3. Horgan J (1995) From complexity to perplexity. Scientific American. 272: 104-109.

4. Lombardi F (2000) Chaos theory, heart rate variability, and arrhythmic mortality. Circulation 101: 8-10. [Crossref]

5. Seely AJ Christou NV (2000) Multiple organ dysfunction syndrome: exploring the paradigm of complex nonlinear systems. Crit Care Med 28: 2193-2200. [Crossref]

6. Higgins JP (2002) Nonlinear systems in medicine. Yale J Biol Med 75: 247-260. [Crossref]

7. Goldberger AL Rigney DR, West BJ (1990) Chaos and fractals in human physiology Sci Am 262: 42-49. [Crossref]

8. Lorenz EN (1963) Deterministic nonperiodic flow. Journal of the Atmospheric Sciences 20: $130-141$.

9. Skinner JE (1994) Low-dimensional chaos in biological systems. Biotechnology (N Y) 12: 596-600. [Crossref]

10. Garfinkel A Chen PS, Walter DO, Karagueuzian HS, Kogan B, et al. (1997) Quasiperiodicity and chaos in cardiac fibrillation. J Clin Invest 99: 305-314. [Crossref]

11. Garfinkel A Spano ML, Ditto WL, Weiss JN (1992) Controlling cardiac chaos. Science 257: 1230-1235. [Crossref]

12. Garlet G, Cardoso C, Silva T, Ferreira B, Ávila-Campos M, Cunha F, et al. (2006) Cytokine pattern determines the progression of experimental periodontal disease induced by Actinobacillus actinomycetemcomitans through the modulation of MMPs, RANKL, and their physiological inhibitors. Oral Microbiology and Immunology 21: $12-20$.

13. Graves DT Cochran D (2003) The contribution of interleukin-1 and tumor necrosis factor to periodontal tissue destruction. J Periodontol 74: 391-401. [Crossref]

14. Garlet GP (2010) Destructive and protective roles of cytokines in periodontitis: a reappraisal from host defense and tissue destruction viewpoints. J Dent Res 89: 13491363. [Crossref]

15. Cochran DL (2008) Inflammation and bone loss in periodontal disease. $J$ Periodontol 79: 1569-1576. [Crossref]

16. Preshaw PM (2008) Host response modulation in periodontics. Periodontol 48: 92-110. [Crossref]

17. Williams RC (1990) Periodontal disease. N Engl J Med 322: 373-382. [Crossref]

18. Golub LM, Lee HM, Lehrer G, Nemiroff A, McNamara TF, et al. (1983) Minocycline reduces gingival collagenolytic activity during diabetes. Preliminary observations and a proposed new mechanism of action. J Periodontal Res 18: 516-526. [Crossref]

19. Golub LM Lee HM, Ryan ME, Giannobile WV, Payne J, et al. (1998) Tetracyclines 
inhibit connective tissue breakdown by multiple non-antimicrobial mechanisms. $A d v$ Dent Res 12: 12-26. [Crossref]

20. Monk E Shalita A, Siegel DM (2011) Clinical applications of non-antimicrobial tetracyclines in dermatology. Pharmacol Res 63: 130-145. [Crossref]

21. Golub LM, Ramamurthy N, McNamara TF, Gomes B, Wolff M, et al. (1984) Tetracyclines inhibit tissue collagenase activity. A new mechanism in the treatment of periodontal disease. J Periodontal Res 19: 651-655. [Crossref]

22. Golub LM Ciancio S, Ramamamurthy NS, Leung M, McNamara TF (1990) Low-dose doxycycline therapy: effect on gingival and crevicular fluid collagenase activity in humans. J Periodontal Res 25: 321-330. [Crossref]

23. Golub LM Ramamurthy NS, McNamara TF, Greenwald RA, Rifkin BR (1991) Tetracyclines inhibit connective tissue breakdown: new therapeutic implications for an old family of drugs. Crit Rev Oral Biol Med 2: 297-321. [Crossref]

24. Lee H-M, Ciancio SG, Tüter G, Ryan ME, Komaroff E, et al. (2004) Subantimicrobia dose doxycycline efficacy as a matrix metalloproteinase inhibitor in chronic periodontitis patients is enhanced when combined with a non-steroidal anti-inflammatory drug. $J$ Periodontol 75: 453-463. [Crossref]

25. Caton J Ryan ME (2011) Clinical studies on the management of periodontal diseases utilizing subantimicrobial dose doxycycline (SDD). Pharmacol Res 63: 114-120. [Crossref]
26. Caton JG Ciancio SG, Blieden TM, Bradshaw M, Crout RJ, et al. (2001) Subantimicrobial dose doxycycline as an adjunct to scaling and root planing: posttreatment effects. J Clin Periodontol 28: 782-789. [Crossref]

27. Gu Y Walker C, Ryan ME, Payne JB, Golub LM (2012) Non-antibacterial tetracycline formulations: clinical applications in dentistry and medicine. J Oral Microbiol 4. [Crossref]

28. Emingil G Gürkan A, Atilla G, Kantarci A (2011) Subantimicrobial-dose doxycycline and cytokine-chemokine levels in gingival crevicular fluid. J Periodontol 82: 452-461. [Crossref]

29. Koppikar RS, Agrawal SV (2013) The effect of sub-antimicrobial dose-doxycycline periodontal therapy on serum inflammatory biomarker C-reactive protein levels in postmenopausal Women: A 2-year, double-blinded, randomized clinical trial. Contemp Clin Dent 4:71. [Crossref]

30. Shinwari MS Tanwir F, Hyder PR, Bin Saeed MH (2014) Host modulation therapeutics in periodontics: role as an adjunctive periodontal therapy. J Coll Physicians Surg Pak 24: 676-684. [Crossref]

31. May RM (1974) Biological populations with nonoverlapping generations: stable points, stable cycles, and chaos. Science 186: 645-647. [Crossref]

Copyright: $(2015$ Dannan A. This is an open-access article distributed under the terms of the Creative Commons Attribution License, which permits unrestricted use, distribution, and reproduction in any medium, provided the original author and source are credited. 